Research Paper

\title{
Variant CD44 expression is enriching for a cell population with cancer stem cell-like characteristics in human lung adenocarcinoma
}

\author{
Makoto Nishino ${ }^{1 \#,}$, Mari Ozaki1" ${ }^{1 \#}$, Ahmed E. Hegab ${ }^{1 凶}$, Junko Hamamoto ${ }^{1}$, Shizuko Kagawa ${ }^{1}$, Daisuke Arai ${ }^{1}$, \\ Hiroyuki Yasuda ${ }^{1}$, Katsuhiko Naoki ${ }^{1}$, Kenzo Soejima ${ }^{1}$, Hideyuki Saya ${ }^{2}$, Tomoko Betsuyaku ${ }^{1}$ \\ 1. Division of Pulmonary Medicine, Department of Medicine, and \\ 2. Division of Gene Regulation, Institute for Advanced Medical Research, Keio University School of Medicine, 35 Shinanomachi, Shinjuku-ku, Tokyo 160-8582, \\ Japan \\ \#These authors contributed equally. \\ †This work was supported by JSPS Grant-in-Aid for Scientific Research (A.E.H. and T.B.) \\ $\triangle$ Corresponding author: ahegab@a2.keio.jp, Division of Pulmonary Medicine, Department of Medicine, Keio University School of Medicine, Shinjuku Ku, \\ Shinanomachi 35 Tokyo 160-8582, Japan. Tel: +81-3-5363-3406, Fax: +81-3-3353-2502 \\ (c) Ivyspring International Publisher. This is an open access article distributed under the terms of the Creative Commons Attribution (CC BY-NC) license \\ (https:// creativecommons.org/licenses/by-nc/4.0/). See http://ivyspring.com/terms for full terms and conditions.
}

Received: 2017.02.19; Accepted: 2017.05.29; Published: 2017.07.01

\begin{abstract}
Background: Preliminary studies have identified cancer stem cells (CSCs) in various cancers and there are several ongoing clinical studies targeting these cells. CD44 (standard or variant isoforms) and/or aldehyde dehydrogenase (ALDH) expression is the most commonly used markers for the identification of CSCs. The goal of the current study was to examine the ability of CD44v, either alone or in combination with ALDH, to identify CSCs within human lung cancer cells lines.

Methods: We examined several lung adenocarcinoma cell lines for the ability of CD44v and/or ALDH expression to enrich for cells with CSC characteristics such as in vitro differential proliferation rate, chemotherapeutic-resistance, tumorsphere formation, and in vivo tumorigenicity. We also compared their in vivo secondary tumor formation, and histological characteristics of their xenograft tumors, and examined their expression of PD-L1, EGFR, XCT, and reactive oxygen species (ROS).

Results: Both CD44 $\mathrm{v}^{\text {high }} / A L D H^{\text {high }}$ and CD44 ${ }^{\text {high }} / A L D H^{\text {low }}$ cells were enriched in cells with CSC characteristics, with the CD44 $\mathrm{v}^{\text {high }} / \mathrm{ALDH} \mathrm{H}^{\text {low }}$ cells being more proliferative and more resistant to chemotherapeutics, whereas $C D 44 v^{\text {high }} / A L D H^{\text {high }}$ cells were more efficient in forming tumorspheres in vitro, in making primary xenograft tumors, and in propagating secondary tumors in vivo. Applying stricter sorting gates to select for cells with the highest CD44v/ALDH expression caused the CD44v high/ALDH ${ }^{\text {low }}$ cells to lose their high proliferation rates and chemotherapeutic resistance ability, but enriched for the tumorsphere-forming cells among the CD44 $v^{\text {high }} / A L D H^{\text {high }}$

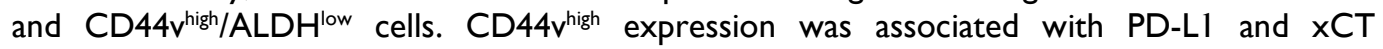
expression in both $\mathrm{H} 1650$ and $\mathrm{HCC} 827$ cells. This association was not modified by ALDH expression in the H1650 cell line. However, in the HCC827 cell line, ALDH expression was negatively associated with PD-L1 and positively associated with $\mathrm{XCT}$ expression.

Conclusion: Lung adenocarcinoma cells with high CD44v expression are enriched for CSCs. Addition of ALDH as an enrichment marker bestowed some CSCs characteristics to CD44 $\mathrm{v}^{\text {high }} / \mathrm{ALDH}^{\text {low }}$ cells and others to $C D 44 \mathrm{v}^{\text {high }} / \mathrm{ALDH}^{\text {high }}$ cells. We propose that lung adenocarcinoma contains different CSCs, each of them endowed with different CSC characteristics.
\end{abstract}




\section{Introduction}

Lung cancer is one of the most lethal cancers worldwide, causing up to three million deaths annually, and therefore, the identification of new targets for lung cancer therapy is an urgent priority. Emerging evidence suggests that the ability of a tumor to grow and propagate is dependent upon a small subset of cells within the tumor, termed cancer stem cells (CSC). The CSC model proposes that tumors have a hierarchical organization in which only some cells indefinitely self-renew and thereby sustain tumor growth. CSCs have been identified in human leukemias, solid breast tumors, the colon, brain and other sites [1, 2]. Knowledge gathered over recent years concerning brain CSCs has prompted the initiation of several clinical trials of experimental vaccines that target cancer stem cells in patients with recurrent glioblastoma [3]. Other clinical trials of drugs targeting breast, gastric, and colon CSCs are ongoing [4]. CD44 and/or aldehyde dehydrogenase (ALDH) are the most commonly used markers for the identification of CSCs [5, 6]. CD44 is a cell surface receptor for hyaluronic acid, and is involved in a wide variety of physiological processes, such as leukocyte homing and activation, cell adhesion and migration [7]. Alternative splicing of CD44 variant exons generates many variant isoforms (CD44v) with variable functions, whereas the standard CD44 (CD44s) isoform contains no variant exons [7, 8]. Expression of CD44v, but not CD44s, in some tumors is associated with tumor progression and metastasis $[9,10]$. ALDHs are a group of enzymes that catalyze the oxidation of aldehydes. High levels of ALDHs are observed in stem cells and CSCs of many tissues and organs [11]. It is thought that markers for CSC isolation are usually the same markers for the same tissue's normal stem cells. This is especially relevant in the lung, as CD44 is a marker for airway basal stem cell isolation, and the expression of ALDH can further select for cells with more stem cell characteristics, in both humans and mice [12, 13]. Despite several recent publications describing putative lung CSCs that express CD44 or ALDH in human surgical samples and cell lines [14-17], several controversies exist, which hinder progression towards clinical applications [18]. These controversies include the absence of a universal lung CSC marker, as most markers are detected in some samples but not others, lack of evidence for an association between the expression of the marker and the patient's prognostic data, and discrepancies between reports of markers that are, and are not, enriched for lung CSCs [18]. In the current study, we employed additional novel strategies to identify lung CSCs. Firstly, we used anti-CD44v antibodies specific to variant 9 (v9) of CD44. This variant is associated with CSCs in ovarian, gastrointestinal, and head and neck cancers [19-21], while anti-CD44 antibodies used in previous studies for the isolation of lung CSCs were non-specific, detecting all isoforms, and therefore, likely making them less sensitive [14, 15]. Second, we used both CD44v and ALDH markers, separately and combined, which has not previously been done in lung CSCs studies. Combining CD44 and ALDH has been shown to be more efficient in detecting CSCs in breast tumors, salivary glands, and pleural mesothelioma [22-24].

Our findings suggest that high CD44v expression marks CSC populations within selective lung adenocarcinoma cell lines. The use of ALDH expression as a second selection marker revealed the possibility of the presence of subtypes of CSCs, with each of them leading on different CSC characteristics. It is likely that some lung adenocarcinomas harbor multiple CSCs, with varying abilities to proliferate, resist chemotherapy, and propagate the tumor.

\section{Methods}

\section{Cell lines}

We examined RNA collected from the following cell lines for CD44v expression: 11 adenocarcinomas (H1975, H1650, PC9, A549, H441, H358, H522, SK-LU1, MCF7, Calu-3 and HCC827), 3 squamous cell carcinomas (SK-MES1, SW900, H520), 1 neuroendocrine (H1770) and 1 epidermoid (Calu-1) cancer cell lines, in addition to normal human bronchial epithelial (NHBE) and BEAS2B non-cancer cell lines. A549, H1650 and HCC827 cell lines were cultured in RPMI (Invitrogen, Carlsbad, CA, USA) supplemented with $10 \%$ fetal bovine serum, penicillin $(100 \mathrm{U} / \mathrm{mL})$ and streptomycin $(100 \mu \mathrm{g} / \mathrm{mL})$ at $37^{\circ} \mathrm{C}$, $5 \% \mathrm{CO}_{2}$, and $95 \%$ humidified air.

\section{RT-PCR}

The expression of CD44v was examined in cell lines by two-step RT-PCR analyses. Total RNA was extracted from all cell lines, using the Qiagen RNeasy mini kit (Qiagen) according to the manufacturer's instructions. Complementary DNA (cDNA) was synthesized from $1 \mu \mathrm{g}$ of total RNA, using the High Capacity RNA to c-DNA kit (ThermoFisher Scientific). The RT-PCR reaction was prepared using the SYBR FAST ABI Prism qPCR Kit (Kapa Biosystems) and the following primers:

CD44 human Forward: TCCCAGACGAAGACA GTCCCTGGAT and CD44 human Reverse: CACTGG GGTGGAATGTGTCTTGGTC.

\section{Flow cytometry}

The CD44v was detected using rat antibodies against human CD44v9 (RV3; 1:500) and mouse 
CD44v8-10 (CD44v10-e16 [RM1]; 1:300) was generated as previously described [20]. Other CD44 (standard and/or other variants) were detected using rat (Biolegend) or mouse (Acris) anti-CD44 antibodies that identify a portion of the protein shared by all isoforms, i.e. panCD44. ALDH staining was performed based on ALDH activity using the Aldefluor ${ }^{\circledR}$ kit (Stem Cell Technologies). The protocol was carried out according to the manufacturers' instructions. Flow cytometric acquisition or sorting was performed using a Gallios flow cytometer (BD) and/or a MoFlo cell sorter (Beckman Coulter) and analyses performed using the FlowJo software.

\section{Immunostaining}

A total of 50,000 unsorted or FACS sorted cells from the different cell lines were cytospun and stained. Paraffin embedded xenograft tumor blocks were cut into $6 \mu \mathrm{m}$ sections and immune-stained as described [25]. The primary antibodies used were CD44v, panCD44, CD34 (Abcam), e-cadherin (BD), EGFR (Santa Cruz), pEGFR (BD), xCT [20] and PD-L1 (Novus Bio). The appropriate Alexa Fluor-coupled secondary antibodies were used in double staining sections. Nuclei were stained with DAPI (Vector labs Burlingame, CA). Slides were examined by fluorescent microscopy using a Zeiss Axiolmager microscope (Carl Zeiss, Jena, Germany).

\section{Cell proliferation assay}

CellTiter 96® AQueous One Solution Cell Proliferation Assay (Promega), which includes 3-(4,5-dimethylthiazol-2-yl)-5-(3-carboxymethoxyphe nyl)-2-(4-sulfophenyl)-2H-tetrazolium, inner salt (MTS) was used according to the manufacturer's instructions to compare the rate of cell proliferation between the different populations. Briefly, in each well, 2,000 cells were seeded in $100 \mu \mathrm{L}$ in a 96-well plate. $20 \mu \mathrm{L}$ of MTS CellTiter 96® AQueous One Solution Reagent was added to the cells. The plate was incubated at $37^{\circ} \mathrm{C}$ for 1 hour. The absorbance was measured at OD490 nm using a plate reader. Triplicate wells were analyzed in each assay.

\section{Chemotherapeutic-resistance test}

A total of 50,000 freshly sorted cells from the different populations from all cell lines were seeded on culture plates and allowed to attach overnight. Cells were then treated with $5 \mu \mathrm{M}$ docetaxel or vehicle. Three days later, both floating and attached cells were collected and the percentages of apoptotic and dead cells were determined using Annexin V and PI staining on a flow cytometer.

\section{In vivo tumorigenicity (xenograft formation)}

Freshly sorted cells $(100,000$ or 10,000$)$ were mixed with an equal volume of matrigel (BD) (in 200 $\mu \mathrm{l})$ and injected subcutaneously into the back of 8 - to 12-week-old recipient mice. Recipient mice used were athymic nude Foxn1nu (hereafter, nude)(Charles River, Wilmington, MA) or NOD.CB17-Prkdcscid/NcrCrl (hereafter, NOD/SCID). Tumor growth was measured every week with a caliper, and was observed for up to 4 months, until the recipient mouse showed signs of debilitation or the tumor reached a maximum of 2,000 $\mathrm{mm}^{3}$. For secondary tumor formation, the primary xenograft tumors were digested into single cell suspensions by mincing and enzyme digestion (dispase [BD] + Liberase [Roche]). Cell suspensions were either stained for CD44 and ALDH then sorted, or used as such for subcutaneous injection into NOD/SCID mice. Mice were examined weekly for secondary tumor formation. All animal use was approved by Keio University ethics committee, and was in accordance with the Interdisciplinary Principles and Guidelines for the Use of Animals in Research, Testing, and Education by the New York Academy of Sciences, Ad Hoc Animal Research Committee.

\section{Tumorspheres}

Freshly sorted cells from the different populations were seeded, in triplicates, into low-attachment $35 \mathrm{~mm}$ plates (BD) in descending dilutions (1:1000, 1:500, 1:100, 1:50, 1:10, 1:1). The whole assay was repeated at least twice from both cell lines and sorting strategies. Cells were cultured in serum-free RPMI medium, supplemented with penicillin $(100 \mathrm{U} / \mathrm{mL})$, streptomycin $(100 \mu \mathrm{g} / \mathrm{mL}), 20$ $\mu \mathrm{g} / \mathrm{ml}$ of insulin, $20 \mu \mathrm{g} / \mathrm{ml}$ EGF and $10 \mu \mathrm{g} / \mathrm{ml}$ of bFGF (Millipore) and 25\% methylcellulose (Sigma) and incubated for 3-6 weeks. Wells with at least one tumorsphere of $200 \mu \mathrm{m}$ diameter or more were recorded as positive and imaged using an inverted microscope.

\section{Reactive oxygen species (ROS) measurement}

Freshly sorted cells from the different populations were examined for ROS levels, using H2DCFDA (6-carboxy-2',7'-dichlorodihydrofluoresce in diaceta) (Invitrogen). A H2DCFDA probe solution $(10 \mu \mathrm{M})$ was prepared and $400 \mu \mathrm{L}$ aliquoted into FACS tubes. The cells were placed into the probe solution and incubated at $37^{\circ} \mathrm{C}$ for $15 \mathrm{~min}$. The cells were examined using a Gallios flow cytometer (BD).

\section{Statistics}

Data from multiple samples per group were expressed as mean $\pm \mathrm{SD}$. The quantification of colony forming efficiency (CFE) and cell-type determination was performed by visual counting under a 
microscope and digital imaging from at least 3 triplicates and 3 independent experiments. The t-test was performed for pairwise comparisons and a $\mathrm{P}$ value of less than 0.05 was considered significant.

\section{Results}

\section{Several lung cancer cell lines express CD44v}

We examined, by RT -PCR, 11 adenocarcinoma, 3 squamous cell carcinoma, 1 neuroendocrine, and 1 epidermoid cancer cell lines, in addition to the NHBE and BEAS2B non-cancer cell lines, for the expression of the putative lung CSC marker CD44v. Six adenocarcinomas, two squamous cell carcinomas, as well as the NHBE cells, expressed variable levels of $C D 44 v$ (Figure 1A). We confirmed the identity of the product amplified by RT-PCR by DNA sequencing for two adenocarcinoma cell lines with high levels of CD44v expression (H1650 and PC9), and found 100\% similarity to the reference sequence for $C D 44 v \mathrm{v} 9$. To confirm the expression at the protein level, we used two antibodies: one specific for CD44v, and the other able to detect all isoforms (panCD44: detects standard and all variant isoforms). By immunostaining and flow cytometry, we confirmed the presence of CD44v protein expression in two of the adenocarcinoma cell lines that showed high $C D 44 v$ expression at the RNA level (H1650 and HCC827) (Figure 1B, C, F, G). We also confirmed the absence of $C D 44 v$ v 9 and the presence of standard or other variant CD44 in an adenocarcinoma cell line that showed no $C D 44 v$ expression at the RNA level (A549) (Figure 1D, E, H). This also confirmed the presence of a range of $C D 44 \mathrm{v}$ expression profiles among cells within the same cell line, with some cells having very high expression levels and others having low or no expression.

1-Calu-1 2-H1975

3, 22-H1650 4-PC9

5,20-A549 6-BEAS2B

7-NHBE 8-9-Water

10-H1770 11-SK-MES1

12-H441 13-H358

$14-\mathrm{H} 522 \quad 15-\mathrm{H} 520$

16-SK-LU1 17-MCF7

18-SW900 19-Calu-3

21-HCC827
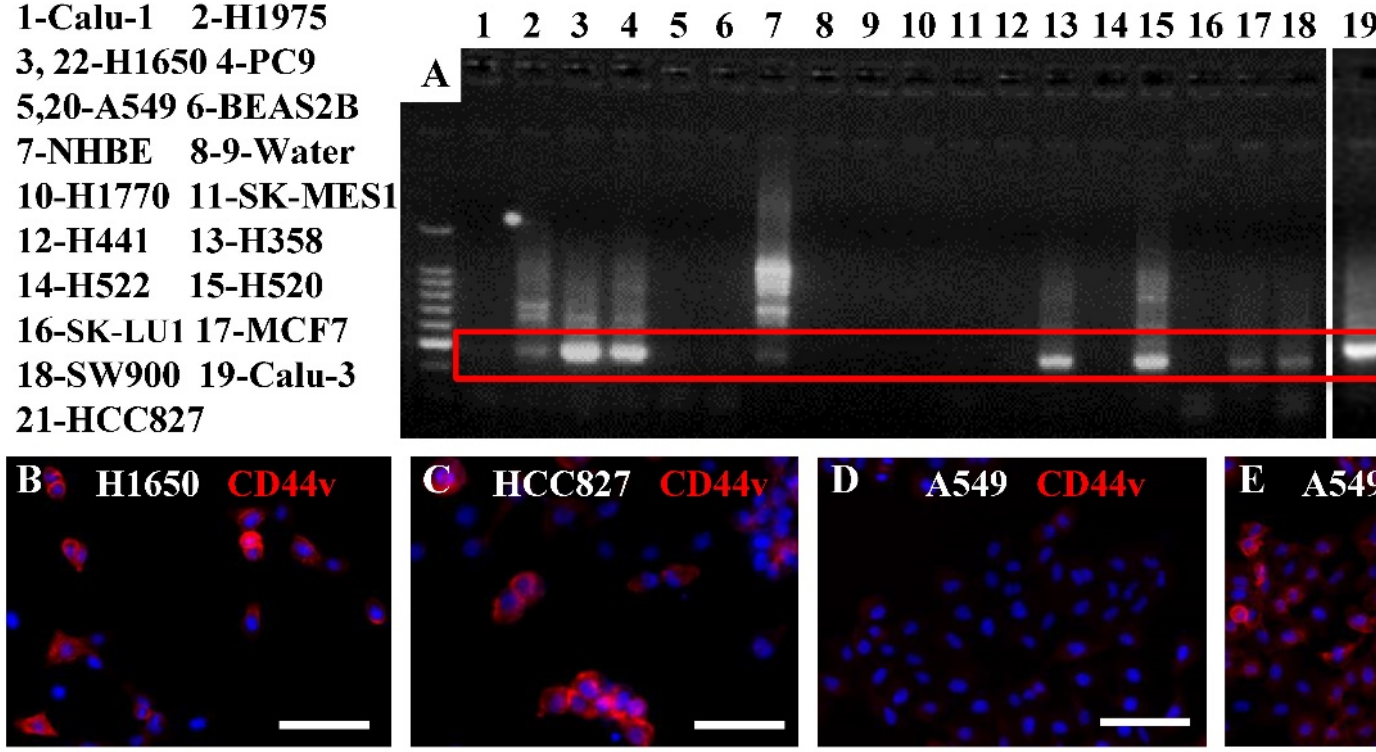

202122
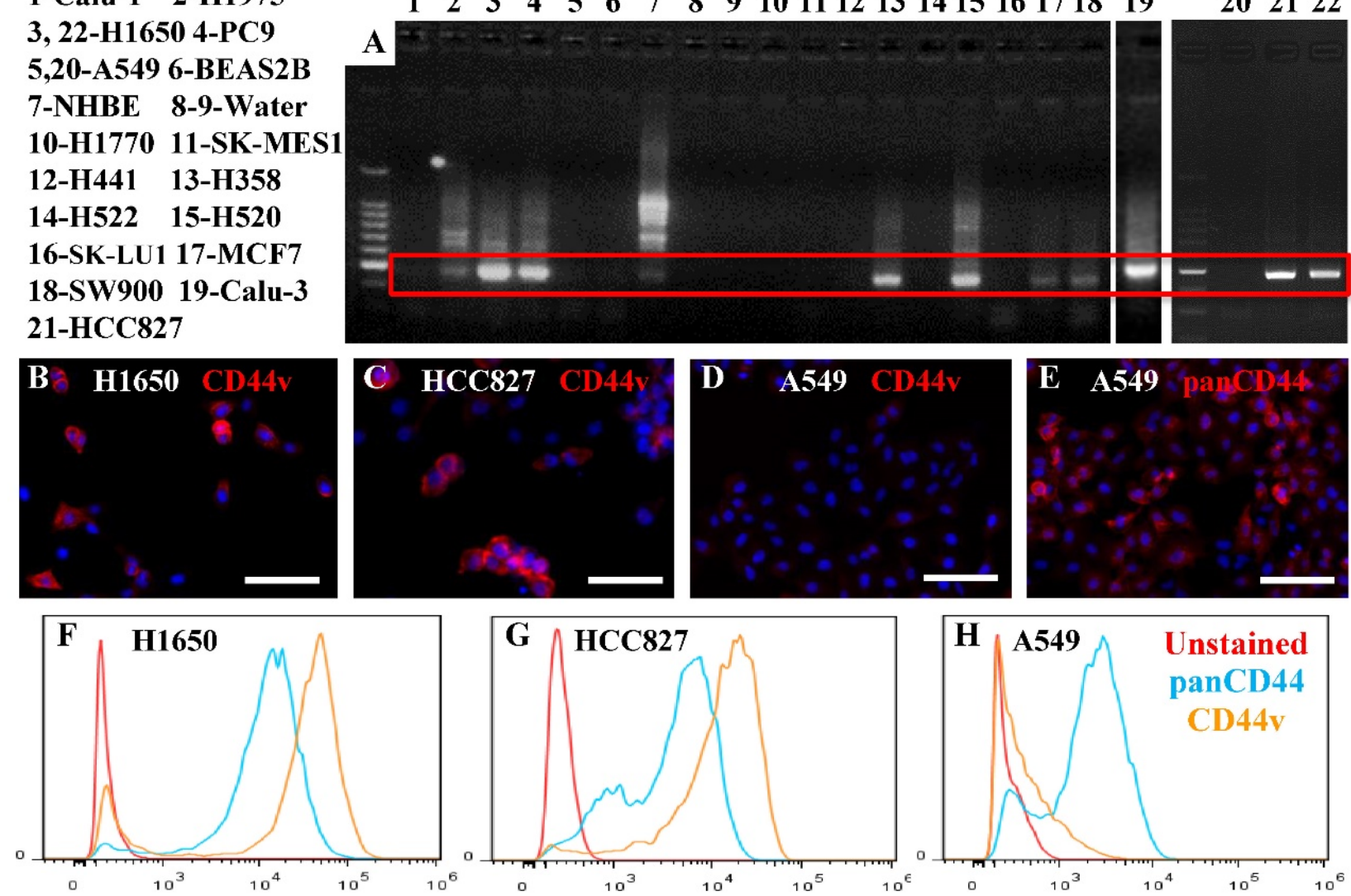

Figure 1: Expression of CD44v in lung cancer cell lines. A) Several lung cancer cell lines, 11 adenocarcinoma (H1975, H1650, PC9, A549, H441, H358, H522, SK-LU1, MCF7, Calu-3, HCC827), 3 squamous cell carcinoma (SK-MES1, H520, SW900), 1 neuroendocrine (H1770) and 1 epidermoid (Calu-1) cancer cell line, in addition to the NHBE and BEAS2B non-cancer cell lines, were examined for CD44v v9 expression using RT-PCR. Cytospun slides containing cells from the H1650 and HCC827 (expressed CD44v RNA) and A549 (did not express CD44v RNA) cell lines were stained with anti-CD44v-specific antibody (B-D) or panCD44 antibody (E). $\mathrm{H1} 650$ and HCC827 cells, but not A549 cells, expressed CD44v. A549 cells expressed other isoform(s). Similar results were seen by flow cytometry (F-H). Scale bars: $50 \mu \mathrm{m}$. 

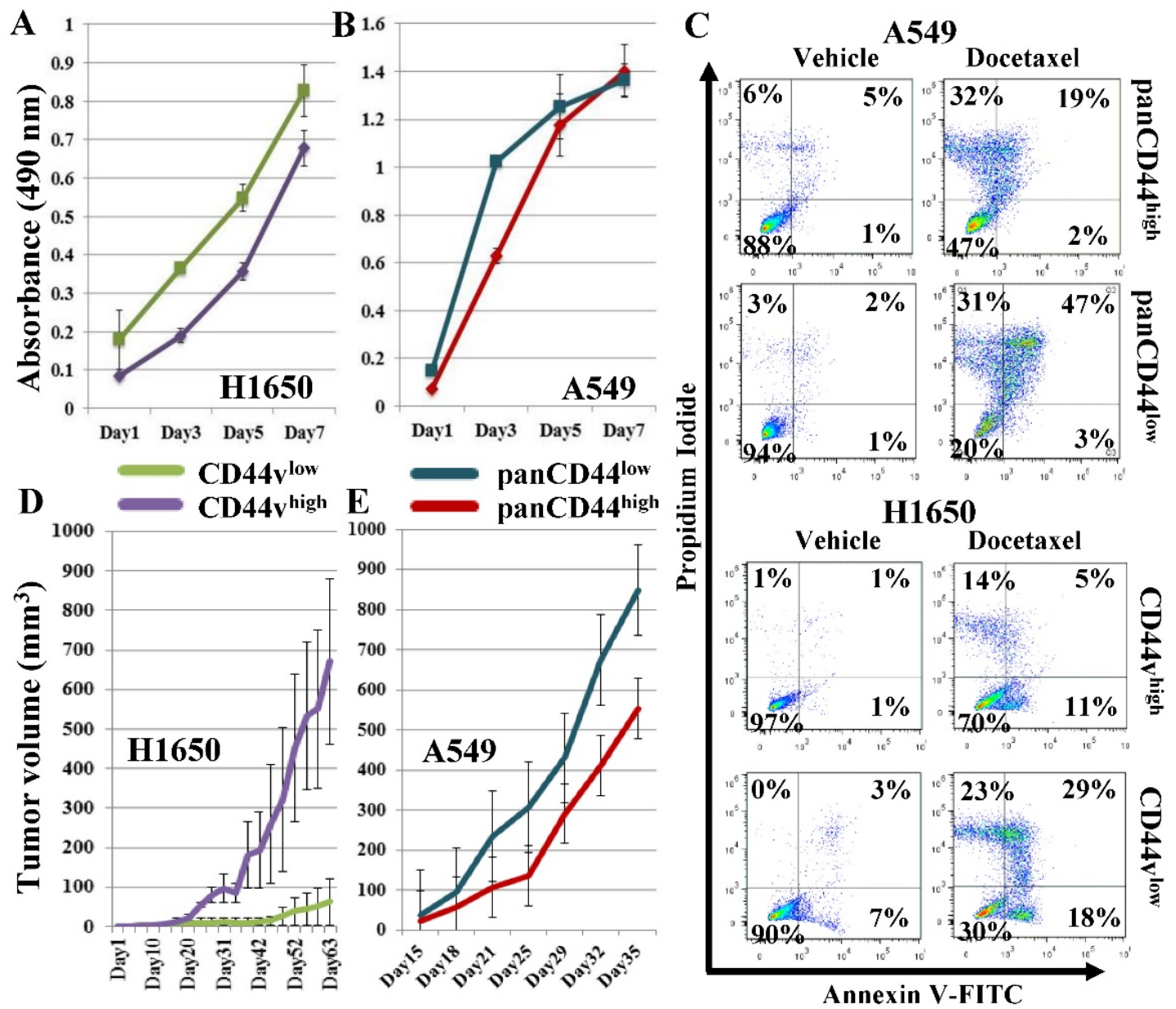

Figure 2: Examining CD44v'high cells for CSC characteristics. CD44v high and CD44vlow cells were sorted from H1650, and panCD44high and panCD44low cells were sorted from A549. (A, B) In vitro cell proliferation MTS assay. (C) Chemotherapeutic-resistance test: viable cells are in the left lower quadrant. (D, E) Xenograft tumor formation in immunocompromised mice, H1650: $n=2$ and A549: $n=3$.

\section{Compared with CD44vlow cells, CD44vhigh cells show some characteristics suggestive of CSC enrichment}

In preliminary studies, we sorted a CD44v-expressing and a non-expressing adenocarcinoma cell line, $\mathrm{H} 1650$ and A549, into $\mathrm{CD} 44 v^{\text {high }}$ and $\mathrm{CD} 44 \mathrm{v}^{\text {low }}$ and panCD44high and panCD44low, respectively. Owing to the CD44 expression in these cell lines not showing clear separation into positive/negative populations, i.e., presenting a continuum of intensity, we sorted the highest and lowest $30 \%$ of CD44-expressing cells from each cell line (Figure S1A-B). We then compared the high versus low populations in several tests suggestive of CSC enrichment. Firstly, we compared their proliferation rates by an in vitro cell proliferation MTS assay. None of the examined populations showed significantly different proliferation rates (Figure 2A, B). Next, we compared the cell populations by a chemotherapeutic-resistance test.
Both the CD44vigh and panCD44 ${ }^{\text {high }}$ cells showed higher percentages of viable cells compared with the CD44v low and panCD44 low cells (Figure 2C), indicating that the presence of CD44 v9 in H1650 cells and other CD44 variant(s) in A549 provides these cells with chemotherapeutic resistance and a survival advantage. Finally, the differential ability of the sorted cells to form tumors in vivo was examined by transplanting 100,000 cells from each population subcutaneously into nude mice. CD44vigh cells from the H1650 cell line formed significantly larger tumors than CD44viow cells, whereas the A549 panCD44low cells tended to form larger tumors than panCD44high cells; however the differences were not statistically significant (Figure 2D, E). As these preliminary experiments suggest that $\mathrm{CD} 44 \mathrm{v}$ expression is a marker that enriches for CSCs in the H1650 cell line, we examined additional markers and techniques that may further enrich for CSCs. 

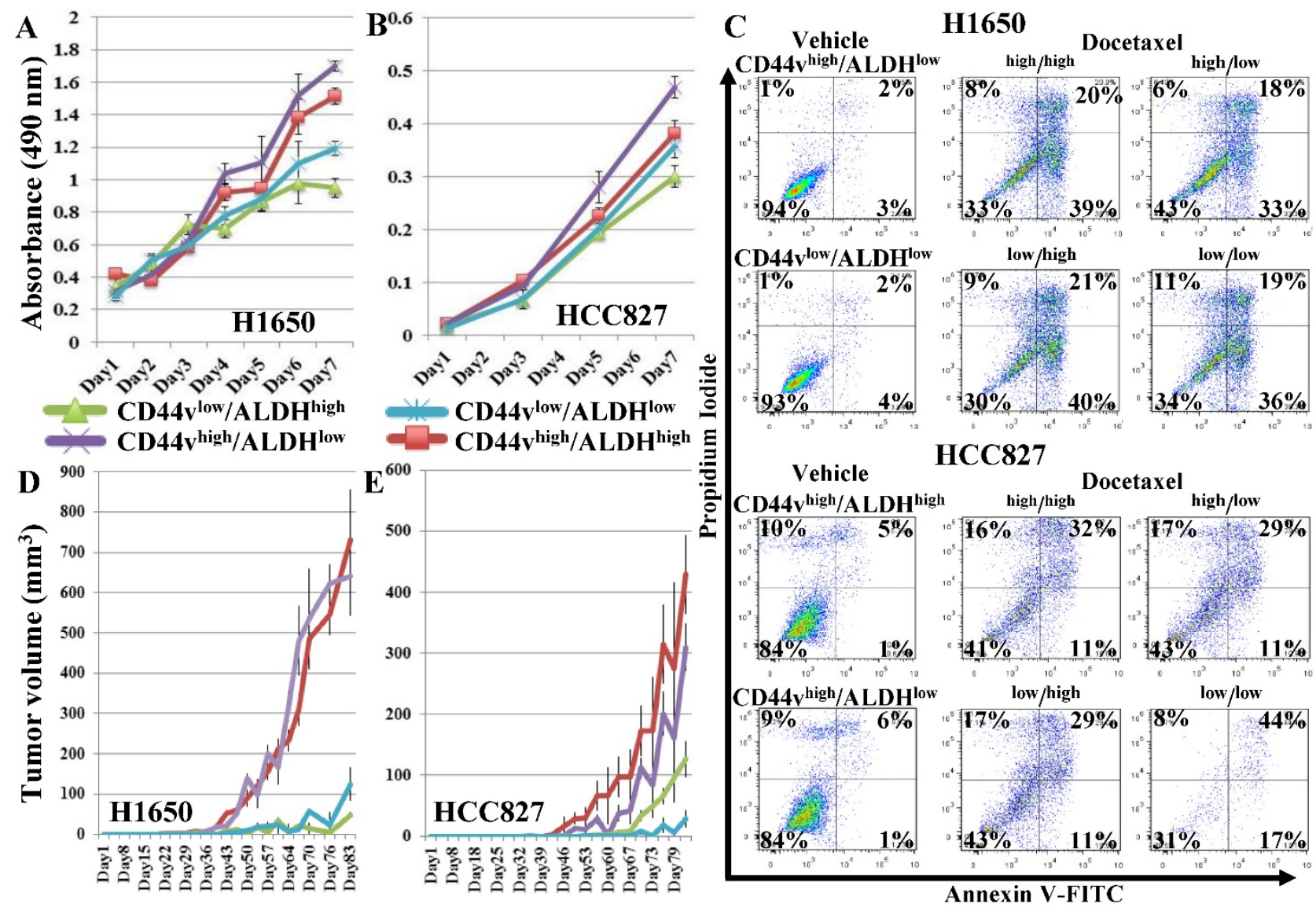

Figure 3: Effect of adding ALDH to CD44v expression on enriching for cells with CSC characteristics. $C D 44 v$ high/ALDHhigh, $C D 44 v^{\text {high}} / A L D H$ low CD44v low/ALDH high, CD44vlow/ALDHlow cells were sorted from the CD44v-expressing cell lines, H1650 and HCC827. (A, B) In vitro cell proliferation MTS assay. (C) Chemotherapeutic-resistance test. (D, E) Xenograft tumor formation in immunocompromised mice, $H 1650: n=9$ and HCC287: $n=9$.

\section{Strategies to enrich for CSCs within the CD44vhigh cell population}

We examined the effect of using ALDH as an additional marker to enrich for CSCs by sorting two CD44v-expressing adenocarcinoma cell lines, H1650 and HCC827, into CD44v $v^{\text {high } / A L D H h i g h, ~}$ $\mathrm{CD} 44 v^{\text {high }} / \mathrm{ALDH}^{\text {low }}, \mathrm{CD} 44 v^{\text {low }} / \mathrm{ALDH} \mathrm{H}^{\text {high }}$ and CD44v low $/ \mathrm{ALDH}^{\text {low }}$ populations. Gates were set to sort the highest and lowest $10-20 \%$ of the CD44/ALDH-expressing cells from each cell line (Figure S1C, D) for subsequent comparisons by various CSC assays. In both cell lines in the in vitro cell proliferation MTS assay, CD44v $v^{\text {high}} / \mathrm{ALDH}^{\text {low }}$ cells showed the highest proliferation rates followed by CD44vigh/ALDH high cells, compared with the other two populations; with the effect tending to be more pronounced in the H1650 cell line (Figure 3A, B). In the chemotherapeutic-resistance test, in the H1650 cell line only, CD $44 \mathrm{v}^{\text {high }} / \mathrm{ALDH}^{\text {low }}$ showed higher percentages of viable cells compared with the other three populations, whereas in the HCC 827 cell line,
CD44v low $/ A L D H$ low showed the lowest viability (Figure 3C). In vivo tumor-formation ability was also compared among the four populations from both cell lines, using the more immunocompromised NOD/SCID mice as recipients and by injecting 100,000 or 1,000 cells from each sorted population in these mice. When the number of injected cells was $100,000, C D 44 v^{\text {high }} / A L D H$ high cells produced the largest tumor nodules, followed by CD44v $v^{\text {high }} / \mathrm{ALDH}^{\text {low }}$ whereas the CD44v low $/ A L D H^{\text {high }}$ and CD44v $v^{\text {low }} /$ ALDH $^{\text {low }}$ formed significantly smaller nodules in both the H1650 and HCC827 cell lines (Figure S2A, B). When the number of injected cells was reduced to 1000, only CD44v $v^{\text {high }} / \mathrm{ALDH}^{\text {high }}$ cells, followed by $\mathrm{CD} 44 v^{\text {high }} / \mathrm{ALDH}^{\text {low }}$ cells, were still able to form large tumor nodules, whereas the CD44v vow $/ \mathrm{ALDH}^{\text {high }}$ and CD44v vow / ALDH ${ }^{\text {low }}$ cells formed no, or much smaller, nodules in both H1650 and HCC827 cell lines (Figure 3D, E). 

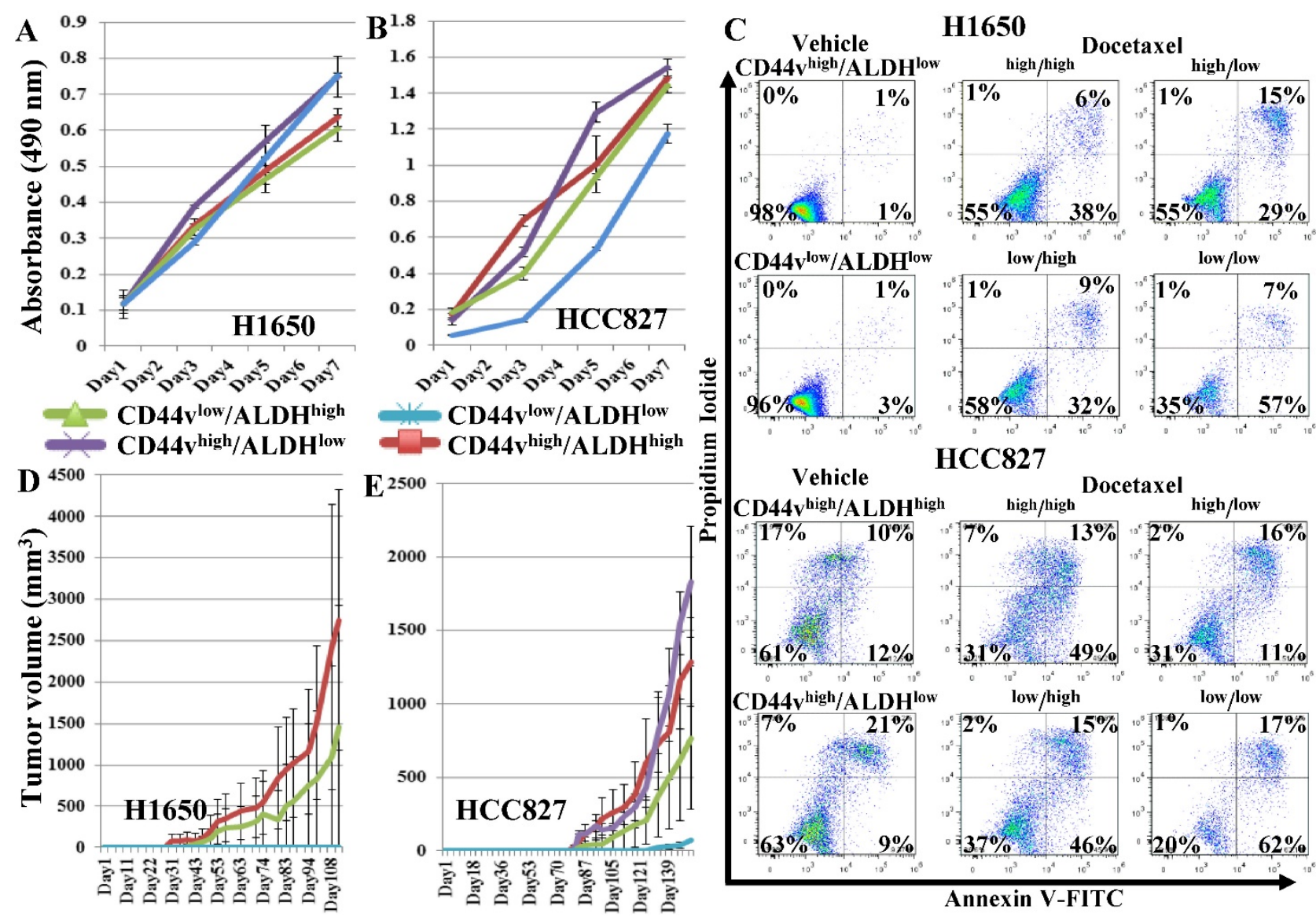

Figure 4: Effect of a more strict gating criteria for the ALDH/CD44v FACS sorting on enriching for cells with CSC characteristics. Strictly gated CD44vigh/ALDH high, CD44vhigh/ALDHlow, CD44vlow/ALDHhigh, CD44vlow/ALDHlow cells were sorted from the CD44v-expressing cell lines, H1650 and HCC82. (A, B) In vitro cell proliferation MTS assay. (C) Chemotherapeutic-resistance test. (D, E) Xenograft tumor formation in immunocompromised mice, $H 1650$ : $n=2$ and HCC287: $n=3$.

To further enrich for CSCs, we sorted the $\mathrm{CD} 44 v^{\text {high }} / \mathrm{ALDH}$ high, $\mathrm{CD} 44 v^{\text {high }} / \mathrm{ALDH}^{\text {low, }}$ $\mathrm{CD} 44 v^{\text {low }} / \mathrm{ALDH}^{\text {high }}, \mathrm{CD} 44 v^{\text {low }} / \mathrm{ALDH}^{\text {low }}$ cells from both the H1650 and HCC827 cell lines, using a stricter gating strategy, setting the gates to sort the highest and lowest $4-5 \%$ of the CD44/ALDH-expressing cells (Figure S5A, B) for subsequent comparisons by CSC assays. In the in vitro cell proliferation MTS assay, no population in either cell line showed higher proliferation ability (Figure $\mathbf{4 A}, \mathbf{B})$. In the chemotherapeutic-resistance test, in both H1650 and HCC827 cell lines, CD44v $v^{\text {high }} / \mathrm{ALDH}^{\text {high, }}$ CD44vigh/ALDH ${ }^{\text {low }}$ and $C D 44 v^{\text {low }} / \mathrm{ALDH}^{\text {high }}$ cells showed similar response to docetaxel treatment, whereas CD44v low $/$ ALDH $^{\text {low }}$ showed lower viability (Figure 4C). In vivo tumor formation ability was compared among the four populations from both cell lines by transplanting 1,000 cells into NOD/SCID mice and examining differential tumor growth. In mice injected with cells from the H1650 cell line, CD44vigh / ALDH ${ }^{\text {high }}$ cells again produced the largest tumor nodules, whereas in mice injected with cells from the HCC827 cell lines, CD44v vigh $/ \mathrm{ALDH}^{\text {low }}$ cells formed the largest tumors, followed by CD44v vigh $/ A L D H{ }^{\text {high }}$ cells (Figure $4 \mathrm{D}, \mathrm{E}$ ). In the anchorage-independent tumorspheres, in H1650 cells, both $\mathrm{CD} 44 v^{\text {high }} / \mathrm{ALDH}^{\text {high }}$ and CD44v $v^{\text {high }} / \mathrm{ALDH}^{\text {low }}$ cells formed tumorspheres in $2 / 3$ wells at 10 -cell density, whereas CD44v low $/ \mathrm{ALDH}^{\text {high }}$ and CD44v vow $/ \mathrm{ALDH}^{\text {low }}$ cells formed no tumorspheres at 50 -cell density and only in $1 / 3$ wells at 100 -cell density. In HCC827 cells, CD44vigh/ ALDH ${ }^{\text {high }}$ cells showed the highest efficiency by forming tumorspheres in $1 / 3$ wells at 10 -cell density, followed by $\mathrm{CD} 44 \mathrm{v}^{\text {high }} / \mathrm{ALDH}^{\text {low }}$ cells, which formed tumorspheres in $2 / 3$ wells at 50 -cell density, then $\mathrm{CD} 44 v^{\text {low }} / \mathrm{ALDH}^{\text {high }}$ which formed tumorspheres in $1 / 3$ wells at 100 -cell density. CD44v vow $/ \mathrm{ALDH}^{\text {low }}$ cells formed no tumorspheres at 100-cell density and only in 1/3 wells at 500-cell density (Figure S6 and S7). Collectively, these data suggest that the stricter gating results in loss of higher proliferation and apoptosis resistance ability, but enriches for tumorsphere-forming cells within the CD44vigh-expressing populations. No effect was seen on the in vivo xenograft tumor formation. 

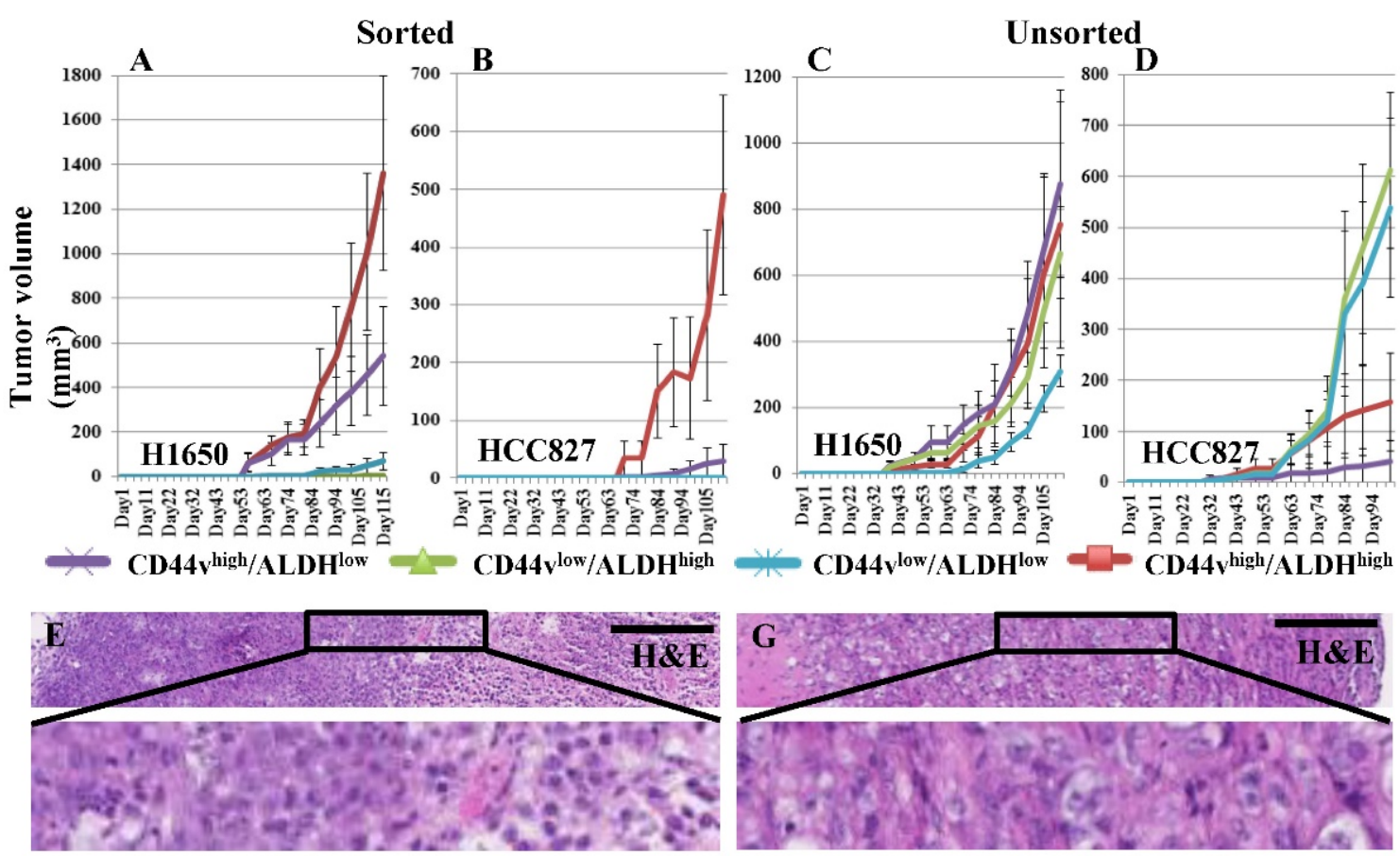

\section{F Peripheral}

Central
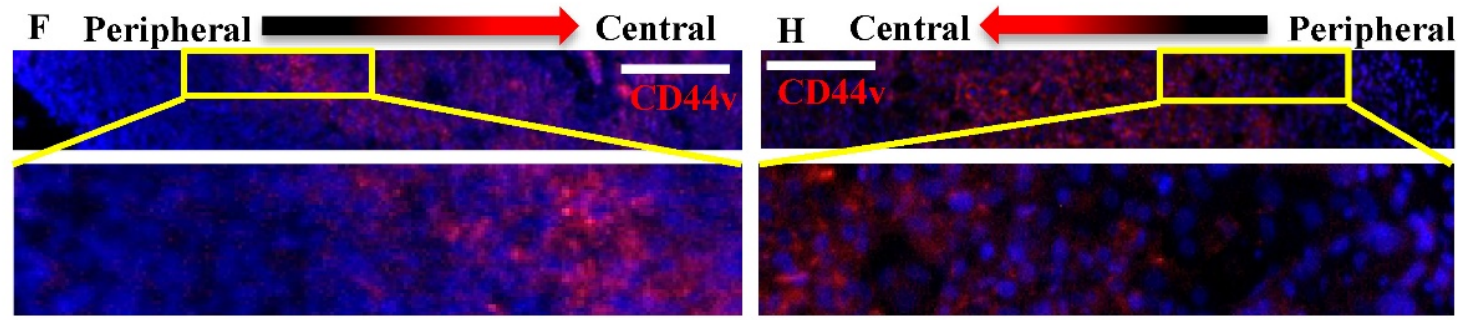

Figure 5: Ability of primary xenografts to propagate secondary tumors. (A, B) Xenograft tumor cells were dissociated from the subcutaneously formed tumors of primary CD44vigh/ALDHhigh cells, from both $\mathrm{H1650}$ and HCC827. The dissociated cells were stained and sorted into CD44vhigh/ALDHhigh, CD44vigh/ALDHlow, CD44vlow/ALDH high and CD44vlow/ALDHlow cells and transplanted into immunocompromised mice. (C, D) Xenograft tumor cells were dissociated from the subcutaneously formed tumors of primary CD44v high/ALDH high, CD44v high/ALDH low, CD44vlow/ALDH high and CD44vlow/ALDH ${ }^{\text {low }}$ cells, from both $\mathrm{H1} 650$ and HCC827. The dissociated cells were transplanted without further sorting into immunocompromised mice. All well-formed primary and secondary tumor nodules were collected and the patterns of CD44v expression was detected using H\&E and immunostaining. (E-H) Representative images from H1650 primary (E, F) and secondary (G, H) tumors. Scale bars: $200 \mu \mathrm{m}$.

\section{In vivo secondary tumor formation}

As CD44vigh $/ A L D H$ high cells appeared to be the population most enriched for xenograft-forming CSCs, we wanted to test whether their tumor initiation capacity can be propagated in vivo. We applied two strategies; the first was to dissociate the primary tumors, formed from CD44vigh / ALDH high cells from both the H1650 and HCC827 cell lines, into single cell suspensions, sort them again into $\mathrm{CD} 44 v^{\text {high }} / \mathrm{ALDH}{ }^{\text {high }}$, CD44v $\mathrm{v}^{\text {high }} / \mathrm{ALDH}^{\text {low }}$, CD44v vow/ALDHhigh and CD44viow/ALDH ${ }^{\text {low }}$ cells and then transplant 1000 cells from each sorted population subcutaneously into NOD/SCID mice. The second strategy was to dissociate all primary tumors, formed from the four populations; $\mathrm{CD} 44 v^{\text {high }} / \mathrm{ALDH}^{\text {high, }} \mathrm{CD} 44 v^{\text {high }} / \mathrm{ALDH}^{\text {low }}$, CD44v vow $/ A L D H^{\text {high }}$ and CD44v low $/ \mathrm{ALDH}^{\text {low }}$ from both the H1650 and HCC827 cell lines, into single cell suspensions then, without sorting, and transplant
1000 cells from each tumor subcutaneously into NOD/SCID mice. Interestingly, when the four populations were sorted from the primary CD44v vigh $/ A L D H$ high cell tumor, CD44v $v^{\text {high }} / \mathrm{ALDH}{ }^{\text {high }}$ cells again formed significantly larger tumors; CD44v $v^{\text {high }} / \mathrm{ALDH}^{\text {low }}$ formed much smaller tumors, whereas CD44v $v^{\text {low }} / \mathrm{ALDH}{ }^{\text {high }}$ and CD44 $v^{\text {low }} / \mathrm{ALDH}^{\text {low }}$ cells formed no tumors at all (Figure 5A, B). On the other hand, when dissociated cells from the four population tumors were transplanted without sorting, no significant difference was seen among the growing secondary tumors in H1650 cells, whereas the cells from $\mathrm{CD} 44 v^{\text {low }} / \mathrm{ALDH}^{\text {high }}$ and CD44v $\mathrm{v}^{\text {low }} / \mathrm{ALDH}^{\text {low }}$ tumors formed relatively larger secondary tumors in HCC827 cells (Figure 5C, D). Apart from considering the difference in size, we also performed immunostaining to examine the tumors for the expression and distribution of CD44v within each nodule to detect 
whether they display a differential pattern based on their population of origin. All tumor nodules, from both cell lines, from all 4 sorted populations, and from both primary (Figure 5E, F) and secondary (Figure $5 \mathrm{G}, \mathrm{H})$ tumors, showed a similar pattern of CD44v expression. CD44v was expressed more towards the center of the nodule and less towards its periphery. Collectively, these data indicate that the $\mathrm{CD} 44 v^{\text {high }} / \mathrm{ALDH}{ }^{\text {high }}$ population harbors the highest number of xenograft-forming CSCs and thus shows the most efficient tumor propagation ability. It also indicates that once the tumor is well established from a CSC-containing population, heterogeneous cells populate the growing tumor as a result of plasticity and differentiation of the transplanted CSCs, eventually producing tumors that are histologically similar and contain similarly few numbers of CSCs.

\section{Comparing the xenografts from the different CD44v/ALDH populations for histological variations}

When examined histologically, many of the growing xenograft tumors showed areas of necrosis towards the tumor center, probably owing to progressive hypoxia/ischemia away from the blood vessels. We wanted to identify whether the size of these necrotic areas is dependent on the size of the tumor (i.e. larger tumors have larger necrotic areas), or on the population which initiated the tumor (i.e. related to CD44v and/or ALDH expression status). Quantification of necrotic areas from all tumors revealed that in H1650, and to a lesser extent, in HCC827, the larger tumor nodules (growing from the transplanted CD44vigh/ALDH high and CD44vigh $/ A L D H^{\text {low }}$ cells) display wider areas of central necrosis, whereas smaller tumor nodules (growing from the transplanted CD44v low $/ \mathrm{ALDH}^{\text {high }}$ and $\mathrm{CD} 44 v^{\text {low }} / \mathrm{ALDH}^{\text {low }}$ cells) display smaller necrotic areas (Figures S8 and S9). As the tumor-stroma interaction is a critical factor in tumor growth, we also wanted to examine whether any of the four populations has a superior ability to induce stroma formation. We stained the xenograft tumors for e-cadherin and CD34, markers that can delineate the cancer 'epithelial' cells from the non-cancer 'stromal' cells. The percentage of stroma within tumor nodules varied from $5-25 \%$ and no subpopulation from either cell line showed a significantly different percentage of stroma within the nodules (Figure S10). These data indicate that although higher levels of $\mathrm{CD} 44 \mathrm{v}$ expression is associated with the ability to form larger xenograft tumors, it is not associated with reduced areas of central necrosis or a more efficient induction of stroma formation.

\section{Potential mechanisms conferring CSC characteristics to the CD44v high-expressing cells}

Several mechanisms by which CD44 bestows CSC characteristics to cells expressing it have been described in head and neck tumors and gastric cancer [20, 28-30]. PD-L1 or 'programmed-death ligand 1' (CD274) is a ligand for PD-1. Binding of PD-L1 to PD-1 inhibits the proliferation of activated T-cells, and thus, it is an essential mechanism in the control of inflammation and autoimmunity. Tumor cells may express PD-L1, which inhibits T-cell activation and allows cancer cells to evade immune detection. PD-L1 has been shown to be preferentially expressed on CD44high CSCs in head and neck tumors, and thus provides them with an immune-evasion ability [28]. We examined the four CD44v/ALDH sorted populations from both $\mathrm{H} 1650$ and HCC827 cell lines for PD-L1 expression. Interestingly, in H1650, PD-L1 expression correlated with $\mathrm{CD} 44 \mathrm{v}$ expression regardless of ALDH expression, i.e., $\mathrm{CD}_{4} \mathrm{v}^{\text {high }} / \mathrm{ALDH}^{\text {high }}$ and $\mathrm{CD} 44 v^{\text {high }} / \mathrm{ALDH}^{\text {low }}$ cells showed high PD-L1 expression (Figure 6A-E). On the other hand, in HCC827, PD-L1 expression correlated with CD44v and inversely correlated with ALDH expression, i.e., only CD44v $v^{\text {high }} / \mathrm{ALDH}^{\text {low }}$ showed high PD-L1 expression whereas the other three populations showed low or no expression (Figure 6F-J). The interaction between CD44 and EGFR has been shown to promote head and neck carcinoma [29]. However, in both H1650 and HCC827, both total and pEGFR were expressed relatively similarly in all the four populations (Figure S11). xCT, a glutamate-cystine transporter, has been shown to control the intracellular levels of reduced glutathione and thus plays a critical role in redox regulation. $\mathrm{CD} 44 \mathrm{v}$ interacts and stabilizes $\mathrm{xCT}$ and thus offers protection to $\mathrm{CD} 44 \mathrm{v}^{\text {high }} \mathrm{CSCs}$ from the high ROS levels in both gastric and head and neck cancers [20, 30]. Interestingly, in H1650, xCT expression correlated with $\mathrm{CD} 44 \mathrm{v}$ expression regardless of the ALDH expression, i.e., CD44 $v^{\text {high }} / \mathrm{ALDH} \mathrm{H}^{\text {high }}$ and CD44vigh/ALDH ${ }^{\text {low }}$ cells showed high $x C T$ expression (Figure 6K-O). On the other hand, in HCC827, xCT was highly expressed in $\mathrm{CD} 44 v^{\text {high }} / \mathrm{ALDH}^{\text {low }}$ cells but was even higher in $\mathrm{CD} 44 v^{\text {high }} / \mathrm{ALDH}{ }^{\text {high, }}$, i.e., $\mathrm{CD} 44 \mathrm{v}$ correlates with $\mathrm{xCT}$ expression and combined expression of CD44v/ALDH provides a boost to XCT levels (Figure 6P-T). However, when ROS levels were compared among the different four populations from both H1650 and HCC827, no significant difference was observed (Figure S12), suggesting that the upregulation of $\mathrm{CD} 44 \mathrm{v}$ and $\mathrm{xCT}$ is not the definitive controller of ROS levels in these lung cancer cell lines. 


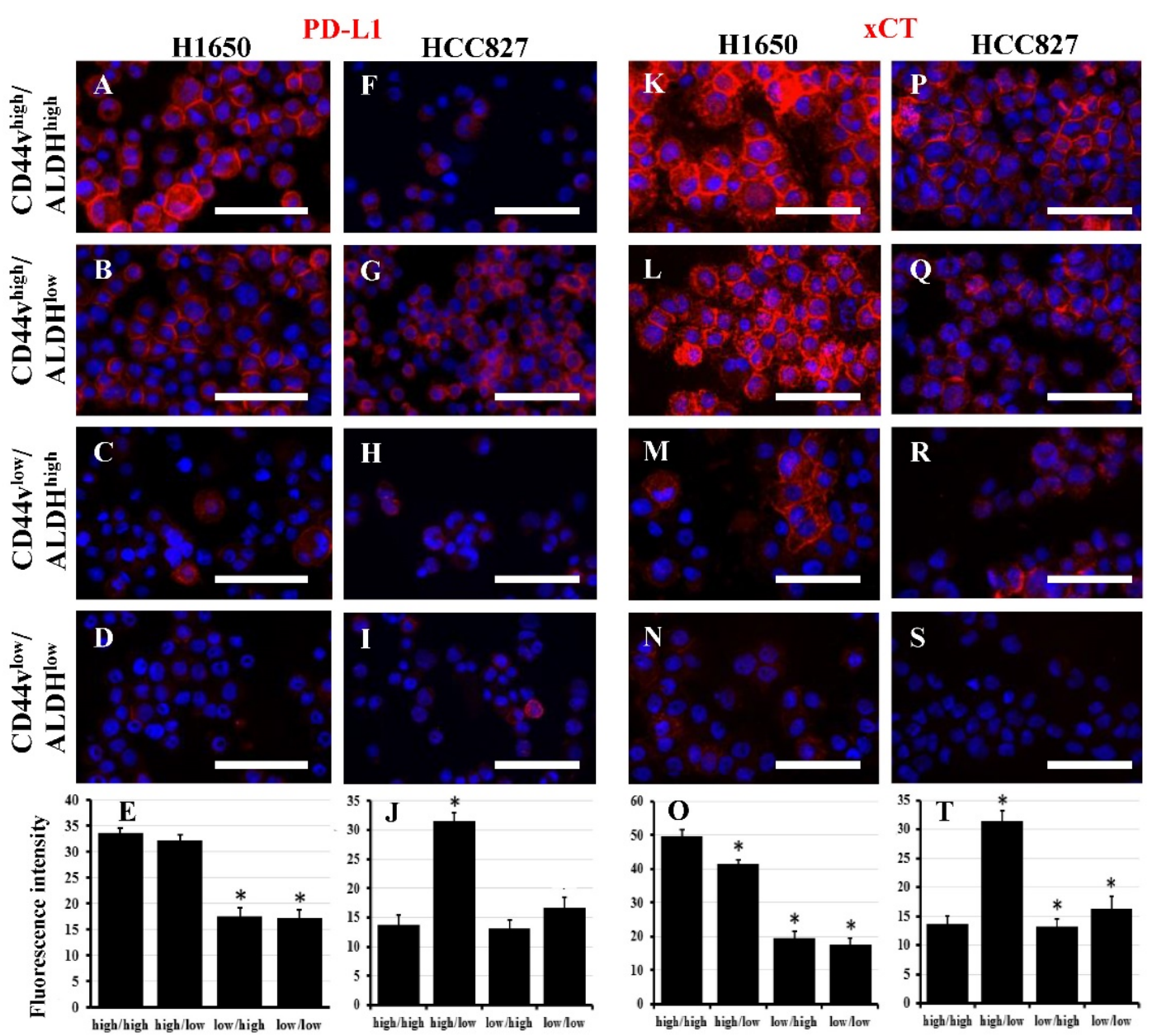

Figure 6: PD-LI and $\mathrm{xCT}$ are potential functional markers associated with CD44vhigh expression. Freshly sorted CD44vhigh/ALDHhigh, CD44vhigh/ALDH How, CD44vlow/ALDH high and CD44vlow/ALDHlow cells from H1650 and HCC827 cell lines were cytospun and immunostained for PD-L1 (A-D and F-I) and $x$ CT (K-N and P-S). Nuclei were stained with DAPI. Scale bars: $50 \mu \mathrm{m}$. (E, J, $\mathbf{O}$ and T) quantification of fluorescence intensity (using Image). *indicates $\mathrm{P}$ value $<0.05$ compared to CD44v vigh/ALDHhigh.

\section{Discussion}

A tumor is not just a 'clone' of identical malignant cells, but rather a complex structure comprising tumor cells, as well as numerous types of stromal and inflammatory cells, which undergo various dynamic interactions, eventually determining the tumor's ability to grow, metastasize, and its response to therapeutic interventions. The presence of a cellular hierarchy within a complex tumor, with the cells at the apex termed CSCs, has been identified in various studies and is responsible for sustaining tumorigenesis and establishing cellular heterogeneity $[1,2]$. However, over the past few years, evidences have accumulated that concept of CSCs are more complex than the earlier simple hypothesis of a (cancer stem) cell on top of a simple tumor cell hierarchy. Currently, the possibility of the presence of multiple CSC phenotypes, the presence of several CSC pools within a tumor, and the ability of CSCs to undergo genetic and/or phenotypic switching have been established [1, 2]. In this study, we provide evidence that lung adenocarcinoma cells with high $\mathrm{CD} 44 \mathrm{v}$ expression are enriched for CSCs. However, the use of ALDH as an additional enrichment marker revealed that the CSCs characteristics examined were split between the $C D 44 v^{\text {high }} / \mathrm{ALDH}^{\text {low }}$ and the $\mathrm{CD} 44 v^{\text {high }} / \mathrm{ALDH}{ }^{\text {high }}$ populations, indicating the presence of two different CSC phenotypes that express CD44v but differ in their levels of ALDH. Similar findings have been described recently for breast CSCs, with mesenchymal-like CSCs expressing CD44 and epithelial-like CSCs expressing ALDH [31]. Our results bear some similarity but also some contradictions to those of a recent study by Liu et al [32]. Their findings seem to assign all the CSC characteristics to the $\mathrm{CD} 44^{\text {high }} / \mathrm{ALDH}^{\text {high }}$ cells, whereas in our study, we found that both CD44vigh/ALDHlow and CD44high $/ \mathrm{ALDH}^{\text {high }}$ cells possessed different characteristics suggestive of CSCs. The reason for this discrepancy could be due to our use of the more CSC-specific v9 CD44 isoform for 
enrichment, whereas they used the non-specific panCD44 that detects all isoforms. Several previous studies have described the identification of CD44-expressing CSCs in human lung cancer surgical samples and cell lines [14-17]. However, in the current study, as well as several previous studies, we identified the complexity of lung CSCs and thus highlight the difficulties that need to be dealt with before proceeding towards clinical application [18]. The presence of intra-tumor heterogeneity and inter-tumor phenotypic heterogeneity have been long described in general for cancer, particularly lung cancer [33-35]. Thus, it is likely that the specificity and sensitivity of markers used for lung CSC identification will vary with tumor type (adeno, squamous, small cell), stage, genetic signature and other phenotypic determinants. It is also likely that the functional role played by a marker in one type of cancer might not be the same for another cancer type. For example, CD44v is a marker for gastric cancer stem cells and its function was thought to be through the regulation of the level of $\mathrm{xCT}$, and thus influencing ROS in CSCs [20]. However, in the current study, although CD44v marked the cells enriched for lung CSCs and its level correlated with the level of $\mathrm{xCT}$ expression, it did not seem to affect the level of ROS in cells with high CD44v expression. It has now been established that the generation of ROS within cancer, mechanisms for their elimination, their cellular interactions, as well as the signaling pathways they influence are complex, and vary markedly from one tumor to another [36]. Our finding that PD-L1 expression correlates with $\mathrm{CD} 44 \mathrm{v}$ expression in both cell lines examined is intriguing. Expression of PD-L1 on non-small cell lung cancer (NSCLC) is associated with poor prognosis [37] and many clinical trials have already tested anti-PD-1/PD-L1 therapies in NSCLC [38]. Despite impressive outcomes in some patients, many others showed no response [38]. Our finding that vCD44-expressing lung adenocarcinoma CSCs specifically overexpress PD-L1 may indicate that vCD44 is a marker able to identify patients who will respond to anti-PD-1/PD-L1 therapies.

In summary, we have examined several lung cancer cell lines for their expression of CD44v. We then compared the ability of high CD44v expression, alone or combined with ALDH expression, to enrich for cells with CSCs characteristics. We found that both $\mathrm{CD} 44 v^{\text {high }} / \mathrm{ALDH}^{\text {high }}$ and $\mathrm{CD} 44 v^{\text {high }} / \mathrm{ALDH}^{\text {low }}$ cells are enriched for cells with CSC characteristics, with the $\mathrm{CD} 44 v^{\text {high }} / \mathrm{ALDH}^{\text {low }}$ cells being more proliferative and more resistant to chemotherapeutics, whereas CD44vigh/ALDH high cells are more efficient in forming xenograft tumors in vivo and tumorspheres in vitro. Applying stricter sorting gates to select for the cells with the highest CD44v/ALDH expression caused CD44vigh $/ \mathrm{ALDH}^{\text {low }}$ cells to lose their high proliferation and chemotherapeutic resistance ability but enriched for tumorsphere-forming cells within the $\mathrm{CD} 44 v^{\text {high }} / \mathrm{ALDH}{ }^{\text {high }}$ and CD44v $v^{\text {high }} / \mathrm{ALDH}^{\text {low }}$ cells. The CD44vigh/ALDH ${ }^{\text {high }}$ population showed the most efficient secondary tumor propagation ability. However, when xenograft tumors were analyzed histologically, CD44v $v^{\text {high }} / \mathrm{ALDH}^{\text {high }}$ expression was not associated with reduced areas of central necrosis or a more efficient induction of stroma formation. CD44vigh expression was associated with PD-L1 and xCT expression in both H1650 and HCC827 cell lines. This association was not modified by ALDH expression in H1650 cells. However, in HCC827 cells, ALDH expression was negatively associated with PD-L1 but positively associated with $\mathrm{xCT}$ expression.

We conclude that lung adenocarcinoma cells with high CD44v expression are enriched for cells with CSCs characteristics. Using ALDH as an additional enrichment marker revealed that $\mathrm{CD} 44 v^{\text {high }} / \mathrm{ALDH}^{\text {low }}$ cells are more proliferative and more resistant to chemotherapeutics, whereas $\mathrm{CD} 44 v^{\text {high }} / \mathrm{ALDH} \mathrm{H}^{\text {high }}$ cells are more efficient at forming xenograft tumors in vivo and tumorspheres in vitro. We propose that lung adenocarcinoma contains different CSCs, each of them endowed with different CSC characteristics.

\section{Supplementary Material}

Supplementary figures.

http://www.jcancer.org/v08p1774s1.pdf

\section{Abbreviations}

CSC: cancer stem cells; ALDH: aldehyde dehydrogenase; ROS: reactive oxygen species; CD44 variant isoform: CD44v.

\section{Acknowledgements}

We thank Mari Fujuwara, Miyuki Yamamoto and Mikiko Shibuya for technical support and the Collaborative Research Resources, Keio University School of Medicine for technical support and reagents.

\section{Author Contributions}

M.N., M.O. A.E.H.: conception and design, collection and/or assembly of data, data analysis and interpretation, manuscript writing; J.H., S.K.: collection and/or assembly of data; K.N., H.Y., K.S.: data analysis and interpretation; T.B.: data analysis and interpretation, financial and administrative support. 


\section{Competing Interests}

The authors have declared that no competing interests exist.

\section{References}

1. Visvader JE, Lindeman GJ. Cancer stem cells: current status and evolving complexities. Cell Stem Cell. 2012 10: 717-28.

2. Kreso A, Dick JE. Evolution of the cancer stem cell model. Cell Stem Cell. 2014 14: 275-91.

3. Xu LW, Chow KK, Lim M, Li G. Current vaccine trials in glioblastoma: a review. J Immunol Res. 2014; 2014: 796856.

4. Dragu DL, Necula LG, Bleotu C, et al. Therapies targeting cancer stem cells: Current trends and future challenges. World J Stem Cells. 2015 7: 1185-201.

5. Yan Y, Zuo X, Wei D. Concise Review: Emerging Role of CD44 in Cancer Stem Cells: A Promising Biomarker and Therapeutic Target. Stem Cells Transl Med. 2015 4: 1033-43.

6. Pors K, Moreb JS. Aldehyde dehydrogenases in cancer: an opportunity for biomarker and drug development? Drug Discov Today. 2014 19: 1953-63.

7. Nagano O, Saya H. Mechanism and biological significance of CD44 cleavage. Cancer Sci. 2004 95: 930-5.

8. Nagano O, Okazaki S, Saya H. Redox regulation in stem-like cancer cells by CD44 variant isoforms. Oncogene 2013 32: 5191-8.

9. Shi J, Zhou Z, Di W, et al. Correlation of CD44v6 expression with ovarian cancer progression and recurrence. BMC Cancer. 2013 13: 182.

10. Orian-Rousseau V. CD44 Acts as a Signaling Platform Controlling Tumor Progression and Metastasis. Front Immunol. 2015 6: 154.

11. Ma I, Allan AL. The role of human aldehyde dehydrogenase in normal and cancer stem cells. Stem Cell Rev. 2011 7: 292-306.

12. Hegab $\mathrm{AE}, \mathrm{Ha} \mathrm{VL}$, Darmawan $\mathrm{DO}$, et al. Isolation and in vitro characterization of basal and submucosal gland duct stem/progenitor cells from human proximal airways. Stem Cells Transl Med. 2012 1: 719-24.

13. Hegab AE, Ha VL, Bisht B, et al. Aldehyde dehydrogenase activity enriches for proximal airway basal stem cells and promotes their proliferation. Stem Cells Dev. 2014 23: 664-75

14. Leung EL, Fiscus RR, Tung JW, et al. Non-small cell lung cancer cells expressing CD44 are enriched for stem cell-like properties. PLoS One. 2010 5: e14062.

15. Wang $P$, Gao $Q$, Suo Z, et al. Identification and characterization of cells with cancer stem cell properties in human primary lung cancer cell lines. PLoS One. 2013 8: e57020.

16. Sullivan JP, Spinola M, Dodge M, et al. Aldehyde dehydrogenase activity selects for lung adenocarcinoma stem cells dependent on Notch signaling. Cancer Res. 2010 70: 9937-48.

17. Shao C, Sullivan JP, Girard L, et al. Essential role of aldehyde dehydrogenase $1 \mathrm{~A} 3$ (ALDH1A3) for the maintenance of non-small cell lung cancer stem cells is associated with the STAT3 pathway. Clin Cancer Res. 2014 20: 4154-66.

18. Alamgeer M, Peacock CD, Matsui W, et al. Cancer stem cells in lung cancer: Evidence and controversies. Respirology. 2013 18: 757-64.

19. Sosulski A, Horn H, Zhang L, et al. CD44 Splice Variant v8-10 as a Marker of Serous Ovarian Cancer Prognosis. PLoS One. 2016 11: e0156595.

20. Ishimoto T, Nagano $\mathrm{O}, \mathrm{Yae} T$, et al. CD44 variant regulates redox status in cancer cells by stabilizing the xCT subunit of system xc(-) and thereby promotes tumor growth. Cancer Cell. 2011 19: 387-400.

21. Aso T, Matsuo M, Kiyohara H, et al. Induction of CD44 variant 9-expressing cancer stem cells might attenuate the efficacy of chemoradioselection and Worsens the prognosis of patients with advanced head and neck cancer. PLoS One. 2015 10: e0116596.

22. Liu S, Cong Y, Wang D, et al. Breast Cancer Stem Cells Transition between Epithelial and Mesenchymal States Reflective of their Normal Counterparts. Stem Cell Reports. 2013 2: 78-91.

23. Cortes-Dericks L, Froment L, Boesch R, et al. Cisplatin-resistant cells in malignant pleural mesothelioma cell lines show ALDHhighCD44+ phenotype and sphere-forming capacity. BMC Cancer. 2014 14: 304.

24. Adams A, Warner K, Pearson AT, et al. ALDH/CD44 identifies uniquely tumorigenic cancer stem cells in salivary gland mucoepidermoid carcinomas. Oncotarget. 2015 6: 26633-50.

25. Hegab AE, Arai D, Gao J, et al. Mimicking the niche of lung epithelial stem cells and characterization of several effectors of their in vitro behavior. Stem Cell Res. 2015 15: 109-21

26. Ponti D, Costa A, Zaffaroni N, et al. Isolation and in vitro propagation of tumorigenic breast cancer cells with stem/progenitor cell properties. Cancer Res. 2005 65: 5506-11.

27. Calvet CY, André FM, Mir LM. The culture of cancer cell lines as tumorspheres does not systematically result in cancer stem cell enrichment. PLoS One. 2014 9: e89644.

28. Lee Y, Sunwoo J. PD-L1 is preferentially expressed on CD44+ tumor-initiating cells in head and neck squamous cell carcinoma. J Immunother Cancer. 2014; 2(Suppl 3): P270.

29. Perez A, Neskey DM, Wen J, et al. CD44 interacts with EGFR and promotes head and neck squamous cell carcinoma initiation and progression. Oral Oncol. 2013 49: 306-13.
30. Yoshikawa M, Tsuchihashi $\mathrm{K}$, Ishimoto $\mathrm{T}$, et al. $\mathrm{xCT}$ inhibition depletes CD44v-expressing tumor cells that are resistant to EGFR-targeted therapy in head and neck squamous cell carcinoma. Cancer Res. 2013 73: 1855-66.

31. Liu S, Cong Y, Wang D, et al. Breast Cancer Stem Cells Transition between Epithelial and Mesenchymal States Reflective of their Normal Counterparts. Stem Cell Reports. 2013 2: 78-91.

32. Liu J, Xiao Z, Wong SK, et al. Lung cancer tumorigenicity and drug resistance are maintained through $\mathrm{ALDH}(\mathrm{hi}) \mathrm{CD} 44(\mathrm{hi})$ tumor initiating cells. Oncotarget. 2013 4: 1698-1711.

33. Gay L, Baker AM, Graham TA. Tumour Cell Heterogeneity. F1000Res. 20165. pii: F1000 Faculty Rev-238.

34. Mabry M, Nelkin BD, Falco JP, et al. Transitions between lung cancer phenotypes--implications for tumor progression. Cancer Cells. 1991 3: 53-8.

35. Krohn A, Ahrens T, Yalcin A, et al. Tumor Cell Heterogeneity in Small Cell Lung Cancer (SCLC): Phenotypical and Functional Differences Associated with Epithelial-Mesenchymal Transition (EMT) and DNA Methylation Changes. PLoS One. 2014 9: e100249.

36. Liou GY, Storz P. Reactive oxygen species in cancer. Free Radic Res. 2010 44: 479-96.

37. Sun JM, Zhou W, Choi YL, et al. Prognostic Significance of PD-L1 in Patients with Non-Small Cell Lung Cancer: A Large Cohort Study of Surgically Resected Cases. J Thorac Oncol. 2016 11: 1003-11.

38. Grigg C, Rizvi NA. PD-L1 biomarker testing for non-small cell lung cancer: truth or fiction? J Immunother Cancer. 2016 4: 48 